\title{
Do Genetic Alterations in Sex Steroid Receptors Contribute to Lacrimal Gland Disease in Sjögren's Syndrome?
}

\author{
Stephen M. Richards and David A. Sullivan*
}

Schepens Eye Research Institute and Department of Ophthalmology, Harvard Medical School, Boston, MA, USA

\begin{abstract}
Background: Defects in sex steroid receptors have been linked to the onset, progression and severity, as well as the sex-related prevalence, of a variety of autoimmune disorders, including lupus, rheumatoid arthritis, multiple sclerosis and diabetes. We hypothesize that defects in estrogen receptor $\alpha$ (ESR1), estrogen receptor $\beta$ (ESR2) and/or the androgen receptor (AR) may also contribute to the development of lacrimal gland autoimmune sequelae in Sjögren's syndrome. To begin to test this hypothesis, we examined whether mutations exist in the coding regions of ESR1, ESR2 and AR transcripts in lacrimal tissues of mouse models of Sjögren's syndrome.

Methods: Lacrimal and submandibular glands were collected from adult MRL/MpJ-Tnfrsf6 ${ }^{\mathrm{lpr}}$, nonobese diabetic and/or $\mathrm{BALB} / \mathrm{c}$ mice. Tissues were pooled according to sex and experiment and processed for cDNA generation. PCR primers were designed to amplify 566-875 base pair segments of the entire open reading frame of each receptor. Segments were amplified, purified and then sequenced. Receptor sequences were assembled and compared to each other and to known NCBI sequences.

Results: Our results show that almost all ESR1, ESR2 and AR sequences in exocrine tissues of male and female autoimmune and non-autoimmune mice were identical to those of NCBI standards. There was a G $\rightarrow$ A shift at position 998 of the ESR2 complete coding sequence in all tissue samples when compared to NCBI reference sequence U81451.1, but this polymorphism was not found in other ESR2 reference sequences.

Conclusions: Our findings indicate that defects in the coding region of sex steroid receptors do not contribute to the pathogenesis of lacrimal gland disease in mouse models of Sjögren's syndrome.
\end{abstract}

Keywords: Sex steroid receptors, lacrimal gland, autoimmune disease, androgen, estrogen.

\section{INTRODUCTION}

Defects in sex steroid receptors have been linked to the onset, progression and severity, as well as the sex-related prevalence, of a variety of autoimmune disorders, including lupus, rheumatoid arthritis, multiple sclerosis and diabetes [1-9]. These defects, which are often due to gene polymorphisms or alternative splicing, may lead to significant changes in the affinity or specificity of ligand binding, nuclear translocation, receptor dimerization, DNA association and transcriptional activation [10-13].

We hypothesize that defects in estrogen receptor $\alpha$ (ESR1), estrogen receptor $\beta$ (ESR2) and/or the androgen receptor (AR) may also contribute to the development of lacrimal gland disease in Sjögren's syndrome. This syndrome is an insidious and currently incurable autoimmune disorder, that occurs primarily in women, and is associated with an extensive lymphocyte accumulation in the lacrimal gland, an immune-mediated destruction and/or dysfunction of acinar and ductal epithelial cells, a precipitous decrease in tear secretion and severe dry eye $[14,15]$. The precise etiology of Sjögren's syndrome is unknown, but the progression

*Address correspondence to this author at the Schepens Eye Research Institute, 20 Staniford Street, Boston, MA 02114, USA; Tel: 617-912-0287; Fax: 617-912-0101; E-mail: david.sullivan@schepens.harvard.edu of this disease has been linked to sex steroid effects $[14,16]$, and to alterations in the structure or function of sex steroid receptors [17]. It is possible that these receptor changes may predispose to the development of autoimmune sequelae, and specifically the lacrimal gland immunopathology and dysfunction, decreased tear secretion and consequent dry eye [14].

To begin to test our hypothesis, we examined whether mutations exist in the coding regions of ESR1, ESR2 and AR transcripts in lacrimal tissues of the MRL/MpJ-Tnfrsf6 $6^{\mathrm{pr}}$ (MRL/lpr) [18] and nonobese diabetic (NOD/LtJ) [19] mouse models of Sjögren's syndrome. For comparative purposes in these experiments, we also evaluated receptor sequences in lacrimal and submandibular glands of nonautoimmune $\mathrm{BALB} / \mathrm{c}$ mice.

\section{MATERIALS AND METHODOLGY}

\section{Animals}

Age-matched $\mathrm{BALB} / \mathrm{c}$ mice were purchased from Taconic Laboratories (Germantown, NY). Young adult MRL/lpr and NOD/LtJ (NOD) mice were obtained from Jackson Laboratory (Bar Harbor, ME). Animals ( $\mathrm{n}=5$ mice/sex/strain/experiment; $n=3$ separate experiments) were housed in constant temperature rooms with fixed light/dark periods of 12 hours length. When indicated 
$(\mathrm{BALB} / \mathrm{c}=9$ weeks old $; \mathrm{MRL} / \mathrm{lpr}=4.6$ months old NOD $=$ 5 months old), animals were sacrificed by $\mathrm{CO}_{2}$ inhalation and salivary and/or lacrimal glands were obtained, pooled according to sex and experiment, frozen in liquid nitrogen and then processed for molecular biological procedures. All studies with mice were approved by The Schepens Eye Research Institute Animal Care and Use Committee and adhered to The Association for Research in Vision and Ophthalmology Resolution on the Use of Animals in Research.

\section{RNA Isolation and cDNA Synthesis}

Glandular total RNA was isolated by using TRIzol reagent (Invitrogen Corp., Carlsbad, CA) and RNAqueous spin columns (Ambion, Austin, Tx). The RNA samples were analyzed spectrophotometrically at 260 and $280 \mathrm{~nm}$ to determine concentration and then evaluated on a RNA 6000 Nano LabChip with an Agilent 2100 Bioanalyzer (Agilent Technologies, Palo Alto, CA), to verify RNA integrity. Aliquots of RNA were exposed to DNase I, then converted to cDNA by using oligo (dT)15 primer (Promega, Madison, WI) and SuperScript III Reverse Transcriptase (Invitrogen). The cDNA was precipitated with alcohol and resuspended in distilled water.

\section{Primer Design and PCR Amplification}

Primers were designed to amplify $566-875$ base pair segments of the entire open reading frame of the AR, ESR1 and ESR2 (Table 1). These designs were accomplished by using Primer3 freeware [20] and reference sequences from the National Center for Biotechnology Information (NCBI) databases (http://www.ncbi.nlm.nih.gov/). The primers were also designed to ensure that: [a] the 5' coding regions were amplified beyond the start/stop codon, which prompted our use of two NCBI sequences for AR and ESR2; and [b] there was a 90-200 base pair overlap on both the 3' and 5' regions of receptor segments (Fig. 1).

Segments were amplified from cDNA with appropriate primers (200 nM), a Platinum Taq DNA Polymerase High Fidelity Kit (Invitrogen) and the following thermocycler program: 1 cycle $\left(94^{\circ} \mathrm{C}\right.$ for 120 seconds), 35 cycles $\left(94^{\circ} \mathrm{C}\right.$ for 45 seconds, $55^{\circ} \mathrm{C}$ for 60 seconds, $72^{\circ} \mathrm{C}$ for 90 seconds) and 1 cycle $\left(72^{\circ} \mathrm{C}\right.$ for 300 seconds). Certain amplifications required the addition of $5 \%$ dimethyl sulfoxide (DMSO) or 1 $M$ betaine (Table 1). An aliquot of each PCR reaction was examined by using a DNA 500 or 1000 LabChip (Agilent) with the 2100 Bioanalyzer, or by utilizing a $1.5 \%$ agarose tris-borate-EDTA gel. The agarose gels were visualized by employing SYBR Safe DNA Gel Stain (Invitrogen) and UV illumination. All amplification reactions produced bands at the expected molecular weight size.

\section{Sequencing and Data Analyses}

Amplicons were purified with a Wizard SV Gel and PCR Clean-Up System (Promega) and their concentrations were determined with a NanoDrop ND-1000 spectrophotometer (NanoDrop Technologies, Wilmington, DE). Amplicon samples, as well as sense and anti-sense primers, were sent to the DNA Sequencing Center for Vision Research at the Massachusetts Eye and Ear Infirmary (Boston, MA). Sequencing reactions were performed on a 3100 Genetic Analyzer (Applied Biosystems, Foster City, CA) with a BigDye Terminator Cycle Sequencing Kit Version 3.0 (Applied Biosystems).

Table 1. Primers and Enhancers Used to Amplify Segments of Androgen and Estrogen Receptor mRNAs

\begin{tabular}{|c|c|c|c|}
\hline Receptor & Sense & Anti-Sense & Enhancer \\
\hline \multicolumn{4}{|l|}{ Androgen } \\
\hline $\mathrm{AR}(\mathrm{NTD} 1)$ & GCTAGCTGCAGATACTACATCATC & GCTGCCTTCGGAGATTACCT & DMSO \\
\hline AR(NTD2) & CTCCGCCGACATTAAAGACA & GCCGTAGTCCAATGGGTTCT & DMSO \\
\hline $\mathrm{AR}(\mathrm{DBD})$ & GACACTTGAGATCCCGTCCT & TCGTTTCTGCTGGCACATAG & None \\
\hline $\mathrm{AR}(\mathrm{LBD} 1)$ & GGACATGCGTTTGGACAGTA & TACTGAATGACCGCCATCTG & None \\
\hline $\mathrm{AR}(\mathrm{LBD} 2)$ & TGTGCATGTGGTCAAGTGG & AACAAAGGCAGAGCCACAAT & None \\
\hline $\mathrm{AR}(\mathrm{LBD} 3)$ & TTAACGTCCTGGAAGCCATT & GGAGCTTGGTGAGCTGGTAG & None \\
\hline \multicolumn{4}{|l|}{ Estrogen 1} \\
\hline ESR1(NTD1b) & GGGAGCCAGTCTGTAACTCG & AGGCATAGTCATTGCACACG & Betaine \\
\hline ESR1.(NTD2) & CTTTCCCCCAGCTCAACAG & AAGGACAAGGCAGGGCTATT & DMSO \\
\hline ESR1(DBD) & ATGACTTGGAAGGCCGAAAT & GGTGGATGTGGTCCTTCTCTT & DMSO \\
\hline ER1(LBD1) & TGGAGATCTTTGACATGTTGCT & GCTAGTCATACATGACATGGGTAAA & DMSO \\
\hline \multicolumn{4}{|l|}{ Estrogen 2} \\
\hline ESR2(NTD1) & CGCAAGACATGGAGATCAAA & TTTTACGCCGGTTCTTGTCT & DMSO \\
\hline ESR2(NTD2) & ACTAGTCCAAGCGCCAAGAG & AGAACGAGGTCTGGAGCAAA & DMSO \\
\hline ESR2(DBD) & GAAGCTGGCTGACAAGGAAC & CTCTGTCGAGCAGCACTCAG & DMSO \\
\hline ESR2(LBD1) & CCAACCTCCTGATGCTTCTT & GGAATGCGAAACGAGTTGAT & DMSO \\
\hline
\end{tabular}

Abbreviations: AR - androgen receptor; ESR1 - estrogen receptor 1; ESR2 - estrogen receptor 2; NTD - N-terminal domain; DBD - DNA binding domain; LBD - ligand binding domain; DMSO - dimethyl sulfoxide. 

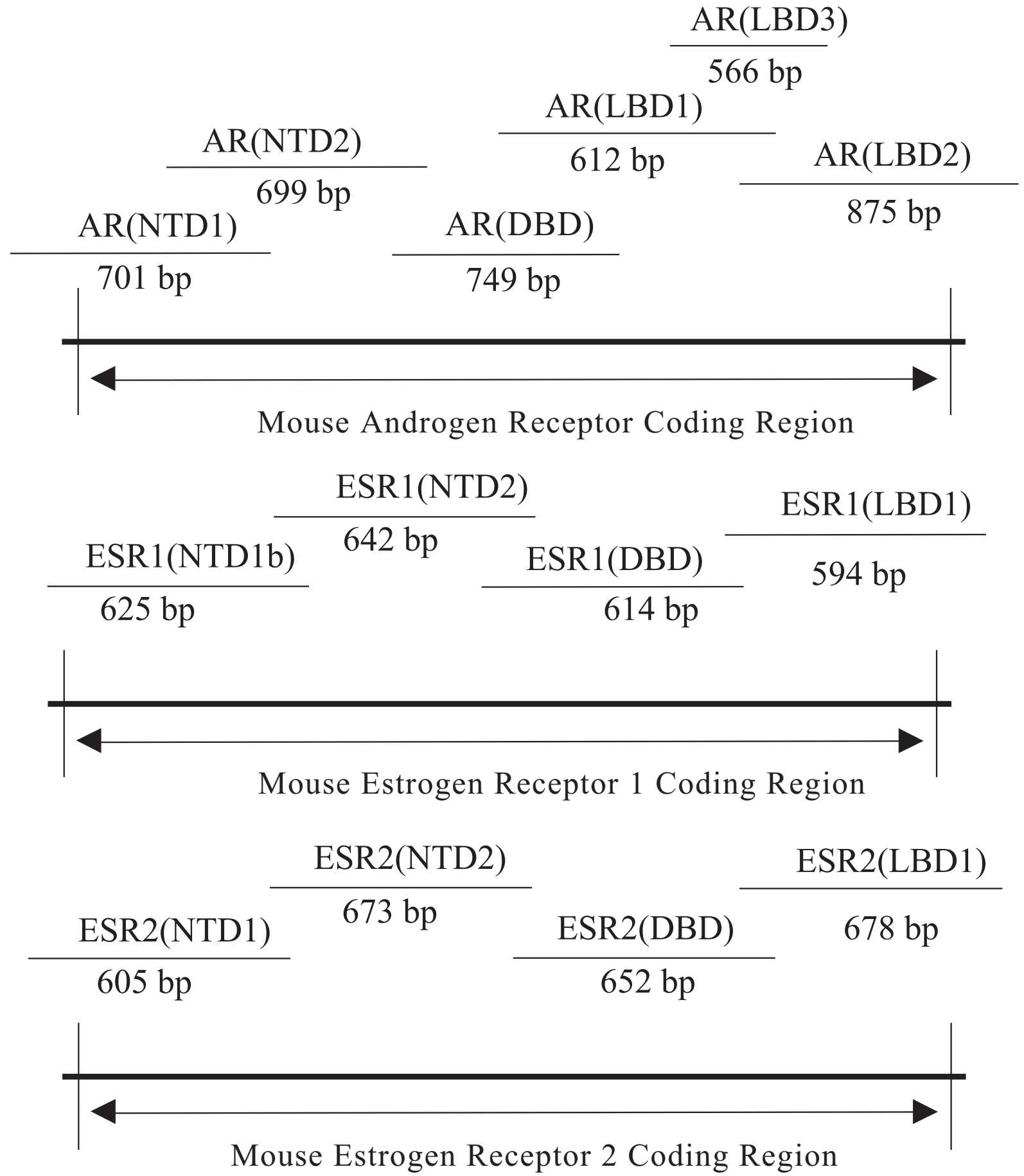

Fig. (1). Amplicon sizes for each of the sex hormone receptors. Abbreviations are defined in the legend to Table 1.

Tracing data were collected with 3100 Data Collection Software Version 1.1 (Applied Biosystems). Amplicons from all cDNA preparations were sequenced at least once by using the sense primers. Additional sequencing was conducted on selected amplicons by utilizing the anti-sense primers. Amplicon sequences were assembled and compared to each other and to known sequences from NCBI with CLC Gene WorkBench (CLC bio, Cambridge, MA). The reference sequences used were NM_013476.2 and X59592.1 for the AR, M38651.1 and NM_007956.2 for ESR1, and AK054413.1, U81451.1 and NM_010157.3 for ESR 2.

\section{RESULTS}

To determine whether defects in sex steroid receptors may contribute to the development of lacrimal gland disease in Sjögren's syndrome, we examined whether mutations exist in the coding regions of ESR1, ESR2 and AR transcripts in lacrimal tissues of male and female MRL/lpr and NOD mice. For comparison, we also evaluated receptor sequences in lacrimal and submandibular glands of non-autoimmune male and female $\mathrm{BALB} / \mathrm{c}$ mice. 
Our results show that almost all ESR1, ESR2 and AR sequences in exocrine tissues of male and female autoimmune and non-autoimmune mice were identical to those of NCBI standards (Fig. 2). More specifically, for the AR all experimental samples produced an assembled sequence identical to NM_013476.2.

For ESR1, the sequences for the male and female $\mathrm{BALB} / \mathrm{c}$ and MRL/lpr submandibular and/or lacrimal glands were identical to those of reference sequence M38651.1. In contrast, the sequences generated from NOD lacrimal glands showed different nucleotides at positions 1299 and 1338 in the ligand binding domain coding region, when compared to the sequence for M38651.1 (Fig. 3). However, the NOD sequence showed complete homology to the ESR1 sequence for NM_007956.2. Given that translation of the M38651.1 and NM_007956.2 sequences produce identical proteins, the nucleotide variations found in NOD lacrimal glands should not result in any functional differences.

For ESR2 there was a $\mathrm{G} \rightarrow \mathrm{A}$ substitution at position 998 of the complete coding sequence in all tissue samples when compared to NCBI reference sequence U81451.1 (Fig. 4), but this polymorphism was not found in other ESR2 reference sequences. The U81451.1 was used as a primary reference sequence for ESR2 because it appears to be the only full length, non-splice variant listed in the NCBI databank.

\section{DISCUSSION}

Polymorphisms in ESR1, ESR2 and AR have been linked to variety of conditions, including breast, endometrial and prostate cancer, cardiovascular disease, diabetes, metabolic syndrome, male infertility, premenstrual dysphoric disorders, depression, cholelithiasis, osteoporosis, preeclampsia, Grave's and Kennedy's diseases, macular degeneration, meibomian gland dysfunction, lupus, rheumatoid arthritis and multiple sclerosis [1-13,21-37]. Indeed, over 300 different mutations have been identified in androgen receptors in non-ocular tissues, which may result in partial or complete insensitivity to androgens [13]. These genetic alterations may be intronic or exonic [38].

However, polymorphisms in the coding regions of ESR1, ESR2 or AR transcripts do not appear play a role in lacrimal gland disease in Sjögren's syndrome. Sex steroid receptors

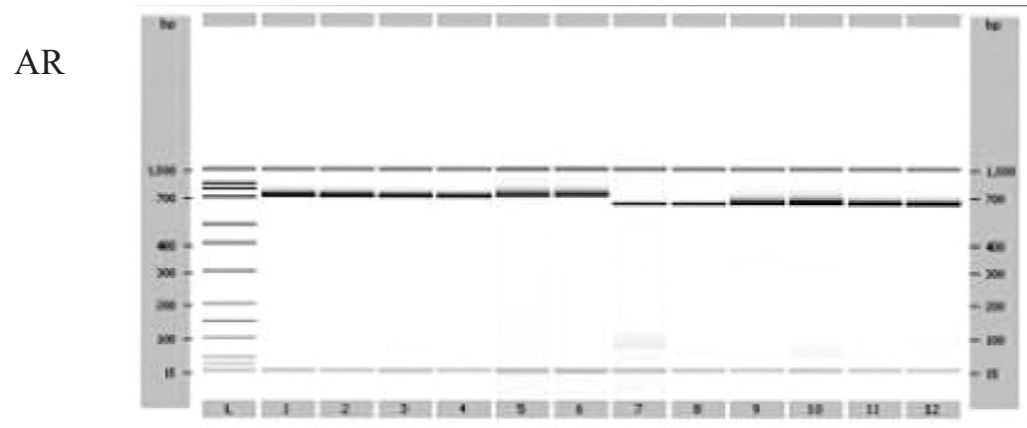
1) $\mathrm{BALB} / \mathrm{c}$ F NTD2
2) BALB/c M NTD2
3) NOD F NTD2
4) NOD M NTD2
5) $\mathrm{MRL} / \mathrm{lpr}$ F NTD2
6) $\mathrm{MRL} / \mathrm{lpr} \mathrm{M}$ NTD2
7) $\mathrm{BALB} / \mathrm{c}$ F LBDI
8) BALB/c M LBDI
9) NOD F LBDI
10) NOD M LBDI
11) MRL/lpr F LBDI
12) MRL/lpr M LBDI

ESR1

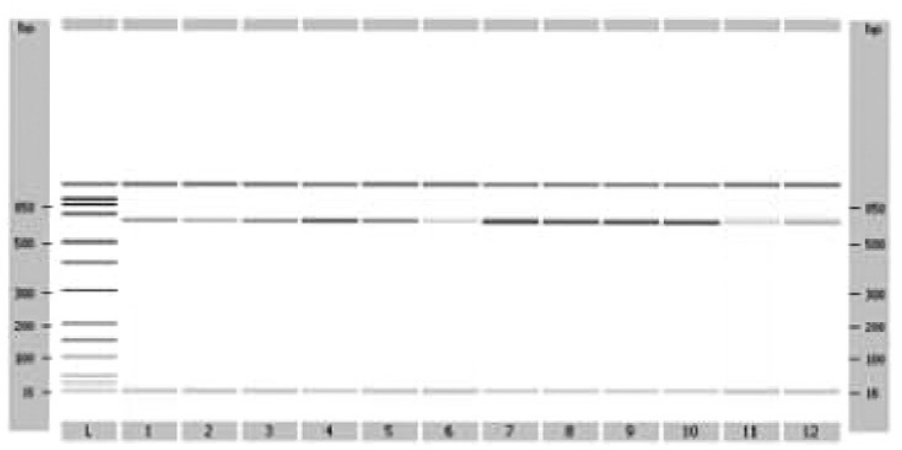

1) $B A L B / c F$ NTD1b

2) BALB/c M NTD1b

3) NOD F NTD1b

4) NOD M NTD1b

5) MRL/lpr F NTD1b

6) MRL/lpr M NTD1b

7) $\mathrm{BALB} / \mathrm{c}$ F DBD

8) BALB/c M DBD

9) NOD F DBD

10) NOD M DBD

11) MPL/lpr F DBD

12) MPL/lpr M DBD

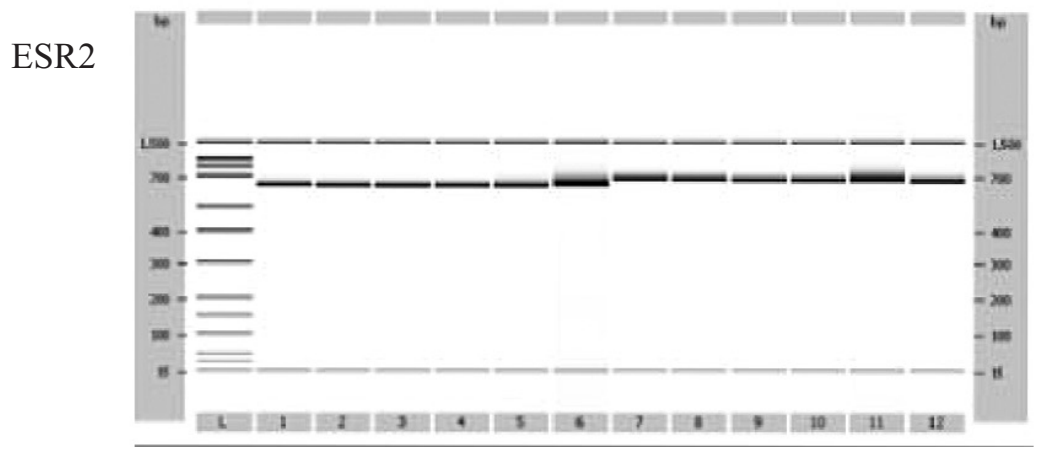
1) $\mathrm{BALB} / \mathrm{c}$ F NTD1
2) BALB/c M NTD1
3) NOD F NTD1
4) NOD M NTD1
5) MRL/lpr F NTD1
6) MRL/lpr M NTD1
7) BALB/c F NTD2
8) BALB/c M NTD2
9) NOD F NTD2
10) NOD M NTD2
11) MPL/lpr F NTD2
12) MPL/lpr M NTD2

Fig. (2). Examples of AR, ESR1 and ESR2 sequences in lacrimal glands of male (M) and female (F) autoimmune and non-autoimmune mice. Images are from the bioanalyzer and molecular weight standards were run in lane "L." Domain abbreviations are reported in the Table $\mathbf{1}$ legend, and anticipated band sizes are shown in Fig. (1). The sizing accuracy is $\pm 10 \%$. 


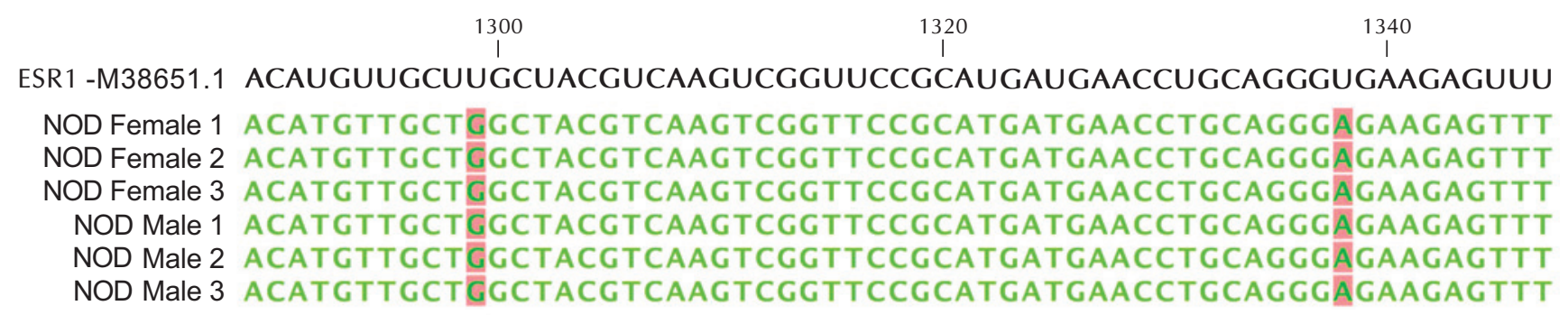

\author{
1300
}

ESR1 -NM_007956.2 ACAUGUUGCUGGCUACGUCAAGUCGGUUCCGCAUGAUGAACCUGCAGGGAGAAGAGUUU

NOD Female 1 ACATGTTGCTGGCTACGTCAAGTCGGTTCCGCATGATGAACCTGCAGGGAGAAGAGTTT NOD Female 2 ACATGTTGCTGGCTACGTCAAGTCGGTTCCGCATGATGAACCTGCAGGGAGAAGAGTTT NOD Female 3 ACATGTTGCTGGCTACGTCAAGTCGGTTCCGCATGATGAACCTGCAGGGAGAAGAGTTT NOD Male 1 ACATGTTGCTGGCTACGTCAAGTCGGTTCCGCATGATGAACCTGCAGGGAGAAGAGTTT NOD Male 2 ACATGTTGCTGGCTACGTCAAGTCGGTTCCGCATGATGAACCTGCAGGGAGAAGAGTTT NOD Male 3 ACATGTTGCTGGCTACGTCAAGTCGGTTCCGCATGATGAACCTGCAGGGAGAAGAGTTT

Fig. (3). Alignment of NOD ESR1 sequences to an NCBI wild type reference sequence. Each number (i.e. 1, 2, 3) represents a different experimental sample. Each sample originated from the lacrimal glands of 5 mice.

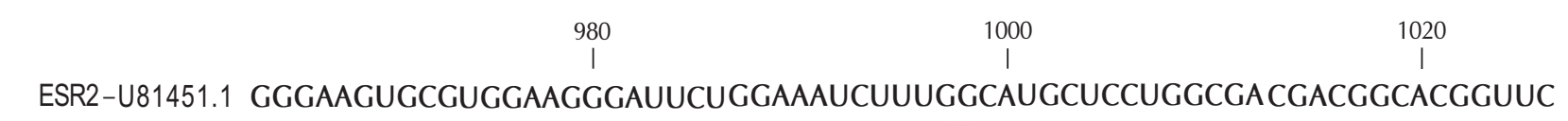

BALB/c Female LG 1 GGGAAGTGCGTGGAAGGGATTCTGGAAATCTTTGÄCATGCTCCTGGCGACGACGGCACGG BALB/c Female LG 2 GGGAAGTGCGTGGAAGGGATTCTGGAAATCTTTGACATGCTCCTGGCGACGACGGCACGG BALB/c Female LG 3 GGGAAGTGCGTGGAAGGGATTCTGGAAATCTTTGACATGCTCCTGGCGACGACGGCACGG BALB/c Male LG 1 GGGAAGTGCGTGGAAGGGATTCTGGAAATCTTTGÄCATGCTCCTGGCGACGACGGCACGG BALB/C Male LG 2 GGGAAGTGCGTGGAAGGGATTCTGGAAATCTTTGÄCATGCTCCTGGCGACGACGGCACGG BALB/C Male LG 3 GGGAAGTGCGTGGAAGGGATTCTGGAAATCTTTGÄCATGCTCCTGGCGACGACGGCACGG BALB/C Female SMG 1 GGGAAGTGCGTGGAAGGGATTCTGGAAATCTTTGACATGCTCCTGGCGACGACGGCACGG BALB/c Female SMG 2 GGGAAGTGCGTGGAAGGGATTCTGGAAATCTTTGÄCATGCTCCTGGCGACGACGGCACGG BALB/c Female SMG 3 GGGAAGTGCGTGGAAGGGATTCTGGAAATCTTTGACATGCTCCTGGCGACGACGGCACGG BALB/c Male SMG 1 GGGAAGTGCGTGGAAGGGATTCTGGAAATCTTTGACATGCTCCTGGCGACGACGGCACGG BALB/c Male SMG 2 GGGAAGTGCGTGGAAGGGATTCTGGAAATCTTTGACATGCTCCTGGCGACGACGGCACGG BALB/C Male SMG 3 GGGAAGTGCGTGGAAGGGATTCTGGAAATCTTTGÄCATGCTCCTGGCGACGACGGCACGG MRL/Ipr Female 1 GGGAAGTGCGTGGAAGGGATTCTGGAAATCTTTGÄCATGCTCCTGGCGACGACGGCACGG MRL/Ipr Female 2 GGGAAGTGCGTGGAAGGGATTCTGGAAATCTTTGÄCATGCTCCTGGCGACGACGGCACGG MRL/Ipr Female 3 GGGAAGTGCGTGGAAGGGATTCTGGAAATCTTTGÄCATGCTCCTGGCGACGACGGCACGG MRL/Ipr Male 1 GGGAAGTGCGTGGAAGGGATTCTGGAAATCTTTGÄCATGCTCCTGGCGACGACGGCACGG MRL/Ipr Male 2 GGGAAGTGCGTGGAAGGGATTCTGGAAATCTTTGACATGCTCCTGGCGACGACGGCACGG MRL/Ipr Male 3 GGGAAGTGCGTGGAAGGGATTCTGGAAATCTTTGÄCATGCTCCTGGCGACGACGGCACGG NOD Female 1 GGGAAGTGCGTGGAAGGGATTCTGGAAATCTTTGÄCATGCTCCTGGCGACGACGGCACGG NOD Female 2 GGGAAGTGCGTGGAAGGGATTCTGGAAATCTTTGACATGCTCCTGGCGACGACGGCACGG NOD Female 3 GGGAAGTGCGTGGAAGGGATTCTGGAAATCTTTGACATGCTCCTGGCGACGACGGCACGG NOD Male 1 GGGAAGTGCGTGGAAGGGATTCTGGAAATCTTTGACATGCTCCTGGCGACGACGGCACGG NOD Male 2 GGGAAGTGCGTGGAAGGGATTCTGGAAATCTTTGACATGCTCCTGGCGACGACGGCACGG NOD Male 3 GGGAAGTGCGTGGAAGGGATTCTGGAAATCTTTGACATGCTCCTGGCGACGACGGCACGG

Fig. (4). Alignment of ESR2 sequences to an NCBI wild type reference sequence. All samples were from lacrimal glands (LG), except for those originating from submandibular glands (SMG).

are ligand-activated transcription factors that mediate sex hormone actions and are comprised of N-terminal, DNAbinding and ligand-binding domains. Our analyses of the mRNA sequences of these domains for the ESR1, ESR2 and $\mathrm{AR}$ in lacrimal tissues of male and female autoimmune mice revealed that functional polymorphisms are absent. Indeed, our data indicate that sex steroid receptor coding region sequences in autoimmune, as well as non-autoimmune, lacrimal glands are essentially identical to those of normal NCBI standards. 
For our studies we evaluated 2 mouse models of Sjögren's syndrome: the MRL/lpr model, which appears to have a disease driven by Th1- and Th2-mediated processes [39], and the NOD model, which seems to have a defect in T cell regulation [40]. Lacrimal glands of MRL/Mp mice contain multifocal and extensive lymphocytic infiltrates, significant tissue disruption and apparent fibrosis [18, 41]. The magnitude of lacrimal gland inflammation in these mice, as with humans, is significantly greater in females as compared to males [42]. This sexual dimorphism has been linked to the effects of sex steroids, with estradiol increasing and testosterone decreasing the extent of inflammation [43].

It has been hypothesized that estradiol through its receptors mediates the progression of autoimmune disease in $\mathrm{MRL} / \mathrm{lpr}$ mice, and that in this disorder, the estrogen receptor is functionally and/or structurally altered [44]. In support of this hypothesis, the ligand-binding affinity of estrogen receptors is significantly elevated [45], whereas the DNAbinding activity of estrogen receptors is significantly reduced [46], in non-ocular tissues of MRL/lpr mice. It is possible that such changes could occur in lacrimal glands of these mice, but given our mRNA data, it would seem that such alterations would have to be post-translational.

In our experiments we also examined lacrimal tissues of NOD mice. We were particularly curious as to whether these animals had a polymorphism in their lacrimal gland androgen receptor. In the NOD strain lacrimal tissues of male mice are far more inflamed than those of female $[42,47]$ and this sex difference appears to be due to androgen action [48]. This anomalous hormone effect is mediated through the lacrimal microenvironment [47], and is in striking contrast to the androgen-induced decrease of inflammation in salivary and pancreatic tissues of NOD mice [47, 49], and in exocrine glands of other murine autoimmune strains [14]. However, as shown in this study, the mRNA sequence of the androgen receptor coding region is normal in lacrimal tissues of NOD mice. It may be that the aberrant androgen action in lacrimal glands of male NOD mice may be due to unique effects of this hormone on the local lymphoid microenvironment, in a manner different than that found in other tissues [50].

\section{CONCLUSION}

In summary, defects in sex steroid receptors are known to play an important role in the sex-related prevalence, as well as the development and progression, of a number of autoimmune disorders [1-9]. Such defects are commonly due to genetic polymorphisms and lead to functional alterations in receptor activity [10-13]. However, our findings in this study indicate that defects in the coding region of sex steroid receptors do not contribute to the pathogenesis of lacrimal gland disease in mouse models of Sjögren's syndrome.

\section{ACKNOWLEDGMENTS}

This research was supported by NIH grant EY05612, a MEEI DNA Sequencing Center Core Grant for Vision Research, and a Research to Prevent Blindness grant to Harvard Medical School's a Department of Ophthalmology.

\section{REFERENCES}

[1] Liu X, Steffensen KR, Sanna A, et al. Anti-inflammatory nuclear receptor superfamily in multiple sclerosis patients from Sardinia and Sweden. Neurobiol Dis 2005; 20: 961-8.

[2] Liu ZH, Cheng ZH, Gong RJ, Liu H, Liu D, Li LS. Sex differences in estrogen receptor gene polymorphism and its association with lupus nephritis in Chinese. Nephron 2002; 90: 174-80.

[3] Niino M, Kikuchi S, Fukazawa T, Yabe I, Tashiro K. Estrogen receptor gene polymorphism in Japanese patients with multiple sclerosis. J Neurol Sci 2000; 179(S 1-2): 70-5.

[4] Kawasaki T, Ushiyama T, Ueyama H, et al. Polymorphic CAG repeats of the androgen receptor gene and rheumatoid arthritis. Ann Rheum Dis 1999; 58: 500-2.

[5] Kassi E, Vlachoyiannopoulos PG, Kominakis A, Kiaris H, Moutsopoulos HM, Moutsatsou P. Estrogen receptor alpha gene polymorphism and systemic lupus erythematosus: a possible risk? Lupus 2005; 14: 391-8.

[6] Johansson M, Arlestig L, Moller B, Smedby T, Rantapaa-Dahlqvist $\mathrm{S}$. Oestrogen receptor $\{$ alpha $\}$ gene polymorphisms in systemic lupus erythematosus. Ann Rheum Dis 2005; 64: 1611-7.

[7] Lee YJ, Shin KS, Kang SW, et al. Association of the oestrogen receptor $\alpha$ gene polymorphisms with disease onset in systemic lupus erythematosus. Ann Rheum Dis 2004; 63: 1244-9.

[8] Ushiyama T, Mori K, Inoue K, Huang J, Nishioka J, Hukuda S. Association of oestrogen receptor gene polymorphisms with age at onset of rheumatoid arthritis. Ann Rheum Dis 1999; 58: 7-10.

[9] Gallagher CJ, Langefeld CD, Gordon CJ, et al. Association of the estrogen receptor- $\alpha$ gene with the metabolic syndrome and its component traits in African-American families: the insulin resistance atherosclerosis family study. Diabetes 2007; 56: 2135-41.

[10] McPhaul MJ, Young M. Complexities of androgen action. J Am Acad Dermatol 2001; 45: S87-94.

[11] Lee DK, Chang C. Endocrine mechanisms of disease: expression and degradation of androgen receptor: mechanism and clinical implication. J Clin Endocrinol Metab 2003; 88: 4043-54.

[12] Deroo BJ, Korach KS. Estrogen receptors and human disease. J Clin Invest 2006; 116: 561-70.

[13] Gottlieb B, Lehvaslaiho, Beitel LK, Lumbroso R, Pinsky L, Trifiro $\mathrm{M}$. The androgen receptor gene mutations database. Nucleic Acids Res 1998; 26: 234-38.

[14] Sullivan DA, Wickham LA, Krenzer KL, Rocha EM, Toda I. Aqueous tear deficiency in Sjögren's syndrome: possible causes and potential treatment. In: Pleyer U, Hartmann C, Sterry W, Eds. Oculodermal Diseases - Immunology of Bullous Oculo-MucoCutaneous Disorders. Buren, The Netherlands: Aeolus Press 1997; 95-152.

[15] 2007 Report of the International Dry Eye WorkShop (DEWS). Ocul Surf 2007; 5: 65-204.

[16] Whitacre C. Sex difference in autoimmune disease. Nat Immunol 2001; 2: 777-80

[17] Greenstein BD. Lupus: why women? J Womens Health Gend Based Med 2001; 10: 233-9.

[18] Hoffman RW, Alspaugh MA, Waggie KS, Durham JB, Walker SE. Sjogren's syndrome in MRL/l and MRL/n mice. Arthritis Rheum 1984; $27:$ 157-65.

[19] Moore PA, Bounous DI, Kaswan RL, Humphreys-Beher MG. Histologic examination of the NOD-mouse lacrimal glands, a potential model for idiopathic autoimmune dacryoadenitis in Sjogren's syndrome. Lab Anim Sci 1996; 46: 125-8.

[20] Rozen S, Skaletsky HJ. Primer3 on the WWW for general users and for biologist programmers. In: Krawetz S, Misener S, Eds. Bioinformatics methods and protocols: methods in molecular biology. Totowa, NJ: Humana Press, 2000: pp. 365-86. Source code available at http://fokker.wi.mit.edu/primer3/.

[21] Conway K, Parrish E, Edmiston SN, et al. Risk factors for breast cancer characterized by the estrogen receptor alpha A908G (K303R) mutation. Breast Cancer Res 2007; 9: R36.

[22] McGrath M, Lee IM, Hankinson SE, et al. Androgen receptor polymorphisms and endometrial cancer risk. Int J Cancer 2006; 118: 1261-8. 
[23] McIntyre MH, Kantoff PW, Stampfer MJ, et al. Prostate cancer risk and ESR1 TA, ESR2 CA repeat polymorphisms. Cancer Epidemiol Biomarkers Prev 2007; 16: 2233-6.

[24] Palazzolo I, Gliozzi A, Rusmini P, et al. The role of the polyglutamine tract in androgen receptor. J Steroid Biochem Mol Biol 2007; [Epub ahead of print].

[25] Rexrode KM, Ridker PM, Hegener HH, Buring JE, Manson JE, Zee RY. Polymorphisms and haplotypes of the estrogen receptorbeta gene (ESR2) and cardiovascular disease in men and women. Clin Chem 2007; 53: 1749-56.

[26] Henttonen AT, Kortelainen ML, Kunnas TA, Nikkari ST. Estrogen receptor-1 genotype is related to coronary intima thickness in young to middle-aged women. Scand J Clin Lab Invest 2007; 67: 380-6.

[27] Mansur AP, Nogueira CC, Strunz CM, Aldrighi JM, Ramires JA. Genetic polymorphisms of estrogen receptors in patients with premature coronary artery disease. Arch Med Res 2005; 36: 511-7.

[28] Aléssio AM, Höehr NF, Siqueira LH, Ozelo MC, de Pádua Mansur A, Annichino-Bizzacchi JM. Association between estrogen receptor alpha and beta gene polymorphisms and deep vein thrombosis. Thromb Res 2007; 120: 639-45.

[29] Huo L, Straub RE, Roca C, et al. Risk for premenstrual dysphoric disorder is associated with genetic variation in ESR1, the estrogen receptor alpha gene. Biol Psychiatry 2007; 62: 925-33.

[30] Kitsiou-Tzeli S, Giannatou E, Spanos I, et al. Steroid hormones polymorphisms and cholelithiasis in Greek population. Liver Int 2007; 27: 61-8.

[31] Geng L, Yao Z, Yang H, Luo J, Han L, Lu Q. Association of CA repeat polymorphism in estrogen receptor beta gene with postmenopausal osteoporosis in Chinese. J Genet Genomics 2007; 34: 868-76.

[32] Molvarec A, Vér A, Fekete A, et al. Association between estrogen receptor alpha (ESR1) gene polymorphisms and severe preeclampsia. Hypertens Res 2007; 30: 205-11.

[33] Kisiel B, Bednarczuk T, Kostrzewa G, et al. Polymorphism of the oestrogen receptor $\beta$ gene (ESR2) is associated with susceptibility to Graves' disease. Clin Endocrinol (Oxf) 2007; [Epub ahead of print].

[34] Sinclair R, Greenland KJ, Egmond S, Hoedemaker C, Chapman A, Zajac JD. Men with Kennedy disease have a reduced risk of androgenetic alopecia. Br J Dermatol 2007; 157: 290-4.

[35] Boekhoorn SS, Vingerling JR, Uitterlinden AG, et al. Estrogen receptor alpha gene polymorphisms associated with incident aging macula disorder. Invest Ophthalmol Vis Sci 2007; 48: 1012-7.

[36] Cermak JM, Krenzer KL, Sullivan RM, Dana MR, Sullivan DA. Is complete androgen insensitivity syndrome associated with alterations in the meibomian gland and ocular surface? Cornea 2003; 22: $516-21$.

[37] Sullivan BD, Evans JE, Cermak JM, Krenzer KL, Dana MR, Sullivan DA. Complete androgen insensitivity syndrome: Effect on hu- man meibomian gland secretions. Arch Ophthalmol 2002; 120 1689-99.

[38] Zavratnik A, Prezelj J, Kocijancic A, Marc J. Exonic, but not intronic polymorphisms of ESR1 gene might influence the hypolipemic effect of raloxifene. J Steroid Biochem Mol Biol 2007; 104 22-6.

[39] D'Alise AM, Auyeung V, Feuerer M, et al. The defect in T-cell regulation in NOD mice is an effect on the T-cell effectors. Proc Natl Acad Sci USA 2008; 105: 19857-62.

[40] Jabs DA, Prendergast RA, Campbell AL, et al. Autoimmune Th2mediated dacryoadenitis in MRL/MpJ mice becomes Th1-mediated in IL-4 deficient MRL/MpJ mice. Invest Ophthalmol Vis Sci 2007 48: 5624-9.

[41] Jabs DA, Alexander EL, Green WR. Ocular inflammation in autoimmune MRL/Mp mice. Invest Ophthalmol Vis Sci 1985; 26 1223-9.

[42] Toda I, Sullivan BD, Rocha EM, Silveira LA, Wickham LA, Sullivan DA. Impact of gender on exocrine gland inflammation in mouse models of Sjögren's syndrome. Exp Eye Res 1999; 69: 35566.

[43] Sato EH, Sullivan DA. Comparative influence of steroid hormones and immunosuppressive agents on autoimmune expression in lacrimal glands of a female mouse model of Sjögren's syndrome. Invest Ophthalmol Vis Sci 1994; 35: 2632-42.

[44] Greenstein B, Roa R, Dhaher Y, et al. Estrogen and progesterone receptors in murine models of systemic lupus erythematosus. Int Immunopharmacol 2001; 1: 1025-35.

[45] Dhaher YY, Greenstein B, de Fougerolles Nunn E, Khamashta M, Hughes GR. Strain differences in binding properties of estrogen receptors in immature and adult BALB/c and MRL/MP-lpr/lpr mice, a model of systemic lupus erythematosus. Int J Immunopharmacol 2000; 22: 247-54.

[46] Thomas T, Gunnia UB, Seibold JR, Thomas TJ. Restoration of the DNA binding activity of estrogen receptor in MRL-lpr/lpr mice by a polyamine biosynthesis inhibitor. Arthritis Rheum 1991; 34: 5562

[47] Hunger RE, Carnaud C, Vogt I, Mueller C. Male gonadal environment paradoxically promotes dacryoadenitis in nonobese diabetic mice. J Clin Invest 1998; 101: 1300-9.

[48] Takahashi M, Ishimaru N, Yanagi K, Haneji N, Saito I, Hayashi Y. High incidence of autoimmune dacryoadenitis in male non-obese diabetic (NOD) mice depending on sex steroid. Clin Exp Immunol 1997; 109: 555-61.

[49] Fox HS. Androgen treatment prevents diabetes in nonobese diabetic mice. J Exp Med 1992; 175: 1409-12.

[50] Bebo BF Jr, Schuster JC, Vandenbark AA, Offner H. Androgens alter the cytokine profile and reduce encephalitogenicity of myelinreactive T cells. J Immunol 1999; 162: 35-40.

(c) Richards and Sullivan; Licensee Bentham Open.

This is an open access article licensed under the terms of the Creative Commons Attribution Non-Commercial License (http://creativecommons.org/licenses/bync/3.0/) which permits unrestricted, non-commercial use, distribution and reproduction in any medium, provided the work is properly cited. 